Jurnal Pustaka Budaya. Vol. 5, No. 2. Juli 2018

Copyright @2018, pISSN: 2355-1186 / eISSN: 2442-7799

Available Online at: https://journal.unilak.ac.id/index.php/pb

\title{
ANALISIS INDEKSASI JURNAL ILMIAH BIDANG PERTANIAN INDONESIA DI DOAJ
}

\author{
Rahmawati \\ Politeknik Negeri Jember, Jember, Indonesia \\ rahmawati08@polije.ac.id
}

Naskah diterima: 25 April; direvisi: 2 Mei; disetujui: 9 Mei.

\begin{abstract}
Abstrak
Penelitian ini bertujuan untuk mendeskripsikan bagaimana indeksasi jurnal ilmiah bidang pertanian yang terbit di Indonesia pada DOAJ.Metode penelitian yang digunakan adalah penelitian kepustakaan.Metode kepustakaan yang dimaksud adalah dengan melakukan penelusuran dokumendokumen secara online.Hal ini dikarenakan indeksasi jurnal yang tersedia dilakukan secara online.Penelusuran dilakukan pada portal DOAJ (http://doaj.org). Hasil penelusuran kemudian disajikan dalam bentuk deskriptif yang dilengkapi dengan tabel dan gambar berdasarkan biaya penerbitan, penerbit, tahun terdaftar pada DOAJ, proses review, dan lisensi. Hasil penelitian menunjukkan bahwa sebanyak 19 jurnal mengenakan biaya penerbitan kepada penulis.berdasarkan penerbit, IPB merupakan penerbit jurnal ilmiah bidang pertanian terbanyak dibandingkan institusi lainnya, yaitu sebanyak 6 jurnal. Berdasarkan tahun terdaftar, Jurnal ilmiah bidang pertanian dari Indonesia terdaftar pertama kali di DOAJ pada tahun 2013, yaitu Jurnal Manajemen \& Agribisnis yang diterbitkan oleh IPB. Sebanyak 14 jurnal yang menggunakan proses peer review. Sedangkan berdasarkan lisensi terbanyak yang digunakan adalah lisensi CC-BY.
\end{abstract}

Kata kunci: indeksasi, jurnal, pertanian, Indonesia, DOAJ.

\begin{abstract}
The aim of this research is to described the DOAJ indexing on agriculture scientific journal that published in Indonesia. The data has been collected from DOAJ on August 2018. It described and represented in article processing charges (APCs), publisher, registered in DOAJ, and it licenses. Result shown that there are 19 scientific journals charged the article processing to the author. IPB is the publisher that the most published the agriculture scientific journal that indexed (6 journals). The first agriculture scientific journal that indexed in DOAj was registered since 2013. There are 14 journals that used peer review while the CC-BY licenses is the common used by the publisher.
\end{abstract}

Keywords: indexing, agriculture, journal, Indonesia, DOAJ.

\section{Pendahuluan}

Istilah jurnal pada awalnya memiliki pengertian catatan harian yang berisi informasi tentang peristiwa-pertistiwa yang terjadi (Lasa Hs., 2009). Literatur lain mendefinisikan jurnal sebagai majalah khusus (Stevenson dan Collin, 2006). Kata ini kemudian berkembang dan menjadi publikasi ilmiah yang memuat hasil kegiatan dalam berbagai ilmu pengetahuan dan teknologi (Lasa Hs., 2009). Jurnal merupakan media komunikasi ilmiah yang sering digunakan oleh para ilmuwan (Bachtiar, 2016). Melalui media jurnal, para peneliti berusaha untuk menginformasikan capaian penelitian ataupun hasil penelitian yang telah mereka lakukan (Hazrati, 2017). Melalui penerbitan artikel jurnal, peneliti berharap hasil penelitian yang mereka paparkan dapat dibaca untuk selanjutnya diaplikasikan oleh masyarakat luas.

Perkembangan jurnal di Indonesia dari tahun ke tahun terbilang cukup menggembirakan. Terlebih lagi jika lebih dikhususkan untuk kategori jurnal elektronik. Tercatat, pasca pemberlakukan regulasi baru terkait akreditasi jurnal ilmiah, jumlah jurnal ilmiah yang diterbitkan ke dalam bentuk elektronik mengalami peningkatan yang cukup signifikan . 
Dikti mencatat bahwa sebelum regulasi tersebut digulirkan pada tahun 2014, jumlah jurnal elektronik berada pada angka 4000-an. Namun setelah pemberlakuan peraturan yang mengharuskan jurnal yang akan diakreditasi haruslah diterbitkan dalam bentuk elektronik, jumlah jurnal ilmiah elektronik meningkat tajam menjadi 9000-an pada tahun 2015 dan terus mengalami peningkatan pada tahun berikutnya (Prasetyawan, 2017).

Agar hasil-hasil penelitian tersebut dapat dibaca oleh masyarakat luas, beberapa pengelola jurnal kemudian mendaftarkan jurnal yang dikelolanya ke beberapa lembaga pengindeks, salah satunya adalah directory open access journal (DOAJ).

DOAJ merupakan salah satu lembaga indeksasi jurnal elektronik yang cukup terkemuka bagi pengelola jurnal di Indonesia. DOAJ pertama kali didirikan pada tahun 2002 oleh Open Society Institute (Marchitelli, Galimberti, Bollini, dan Mitchell, 2017). Tidak semua jurnal yang diterbitkan dapat terdaftar pada lembaga ini. Suatu jurnal perlu melalui serangkaian proses review agar dapat terindeks di DOAJ.

Pada awalberdirinya, untuk dapat terdaftar di DOAJ, pengelola jurnal harus mengisi form yang berisi enam pertanyaan terkait informasi jurnal yang bersangkutan (Olijhoek, 2015). Setiap pengelola jurnal diharuskan untuk menampilkan informasi yang jelas terkait jurnal yang dikelolanya. Saat ini, DOAJ mewajibkan setiap pengelola jurnal untuk mengisi form online yang berisi 58 kolom isian untuk mendaftar. Setelah melakukan pendaftaran, tim reviewer DOAJ akan melakukan peninjauan terkait informasi yang telah diberikan. Hasil peninjauan kemudian akan dikeluarkan selambat-lambatnya dalam 6 bulan sejak suatu jurnal didaftarkan.

Saat ini, Indonesia menempati urutan kedua setelah Inggris sebagai negara penerbit jurnal terbesar yang terdaftar di DOAJ. Tercatat sebanyak 1348 jurnal yang berasal dari Indonesia terindeks di DOAJ. Jurnal tersebut berasal dari berbagai subjek bidang ilmu pengetahuan.

Indonesia merupakan negara agraris. Oleh karena itu, pertanian menjadi salah satu topik unggulan pada riset skala nasional. Melihat kondisi tersebut, pada artikel ini, penulis tertarik untuk mengkaji indeksasi jurnal ilmiah bidang pertanian yang berasal dari Indonesia dan terindeks pada DOAJ.

\section{Metode}

Penelitian ini merupakan penelitian kualitatif. Data dikumpulkan melalui studi dokumentasi. Studi dokumentasi yang dimaksud adalah melakukan penelusuran jurnal ilmiah bidang pertanian yang berasal dari Indonesia pada situs DOAJ. Data yang diperoleh kemudian diinterpretasikan dengan mengelompokkanya berdasarkan biaya penerbitan, penerbit, tahun terdaftar pada DOAJ, proses review, dan lisensi yang digunakan. Hasil pengelompokan kemudian disajikan dalam bentuk tabel dan gambar.

\section{Hasil dan Pembahasan}

Saat ini, terdapat 11.969 jurnal yang terindeks DOAJ. Berdasarkan hasil penulusuran diperoleh hasil bahwa terdapat 36 jurnal ilmiah bidang pertanian yang diterbitkan di Indonesia dan terindeks di DOAJ. Jumlah tersebut memberikan kontribusi sebesar 2,67\% dari keseluruhan jurnal yang terindeks DOAJ dan diterbitkan di Indonesia. Sedangkan untuk tingkat internasional, jurnal ilmiah bidang pertanian dari Indonesia memberikan kontribusi sebesar 19,35\% untuk jurnal ilmiah bidang pertanian yang terindeks DOAJ.

Tabel 1 Jumlah Jurnal Ilmiah Bidang Pertanian yang terbit di Indonesia dan Kontribusinya pada DOAJ

\begin{tabular}{|c|c|c|c|}
\hline No. & Kategori & Jumlah & $\begin{array}{c}\text { Kontribusi } \\
(\%)\end{array}$ \\
\hline 1 & $\begin{array}{l}\text { Jurnal Ilmiah } \\
\text { Terindeks } \\
\text { DOAJ }\end{array}$ & 11.969 & 0,30 \\
\hline 2 & $\begin{array}{l}\text { Jurnal Ilmiah } \\
\text { Bidang } \\
\text { Pertanian } \\
\text { terindeks DOAJ }\end{array}$ & 186 & 19,35 \\
\hline 3 & $\begin{array}{l}\text { Jurnal Ilmiah } \\
\text { Bidang } \\
\text { Pertanian dari } \\
\text { Indonesia } \\
\text { terindeks DOAJ }\end{array}$ & 36 & - \\
\hline 4 & $\begin{array}{l}\text { Jurnal Ilmiah } \\
\text { dari Indonesia } \\
\text { terindeks DOAJ }\end{array}$ & 1.348 & 2,67 \\
\hline
\end{tabular}

Sumber: doaj.org, data diolah 2018 
Data di atas menunjukkan bahwa secara kuantitatif, jumlah jurnal ilmiah yang terindeks DOAJ masih tergolong minim. Terlebih lagi, jika dibandingkan dengan jumlah jurnal ilmiah bidang pertanian yang terdaftar di PDII-LIPI (http://issn.pdii.lipi.go.id/) yang berjumlah lebih dari 900 jurnal. Jika diasumsikan jurnal tersebut terbagi ke dalam dua kategori, yaitu jurnal tercetak dan jurnal elektronik, maka terdapat 400an jurnal ilmiah bidang pertanian yang diterbitkan dalam bentuk elektronik dan telah memiliki e-ISSN. Hal tersebut berarti bahwa terdapat \pm 300 an jurnal ilmiah bidang pertanian yang diterbitkan dalam bentuk elektronik dari Indonesia belum terdaftar di DOAJ. Berikut ini adalah daftar jurnal ilmiah bidang pertanian yang diterbitkan di Indonesia dan terindeks DOAJ.

Tabel 2 Daftar Jurnal Ilmiah Bidang Pertanian dari Indonesia di DOAJ

\begin{tabular}{|c|c|c|}
\hline No. & Nama Jurnal & Alamat \\
\hline 1 & $\begin{array}{l}\text { Jurnal } \\
\text { Agronomi } \\
\text { Indonesia }\end{array}$ & $\begin{array}{l}\text { http://jai.ipb.ac.id } \\
\text { /index.php/jurnala } \\
\text { gronomi/index }\end{array}$ \\
\hline 2 & AGRISE & $\begin{array}{l}\text { http://agrise.ub.ac. } \\
\text { id }\end{array}$ \\
\hline 3 & $\begin{array}{l}\text { Jurnal } \\
\text { Teknologi \& } \\
\text { Industri Hasil } \\
\text { Pertanian }\end{array}$ & $\begin{array}{l}\text { http://jurnal.fp.uni } \\
\text { la.ac.id/index.php/ } \\
\text { JTHP/index }\end{array}$ \\
\hline 4 & $\begin{array}{l}\text { Jurnal } \\
\text { Pertanian } \\
\text { Agros }\end{array}$ & $\begin{array}{l}\text { http://e- } \\
\text { journal.janabadra. } \\
\text { ac.id/index.php/JA }\end{array}$ \\
\hline 5 & $\begin{array}{l}\text { Research } \\
\text { Journal of Life } \\
\text { Science }\end{array}$ & $\begin{array}{l}\text { http://rjls.ub.ac.id } \\
\text { /index.php/rjls }\end{array}$ \\
\hline No. & Nama Jurnal & Alamat \\
\hline 6 & $\begin{array}{l}\text { Journal of } \\
\text { Agribusiness } \\
\text { and Rural } \\
\text { Development } \\
\text { Research }\end{array}$ & $\begin{array}{l}\text { http://journal.umy } \\
\text {.ac.id/index.php/a } \\
\text { g/index }\end{array}$ \\
\hline 7 & $\begin{array}{l}\text { Jurnal } \\
\text { Agribisnis } \\
\text { Indonesia }\end{array}$ & $\begin{array}{l}\text { http://journal.ipb. } \\
\text { ac.id/index.php/ja } \\
\text { gbi/ }\end{array}$ \\
\hline 8 & $\begin{array}{l}\text { Jurnal Ilmiah } \\
\text { Agribisnis }\end{array}$ & $\begin{array}{l}\text { https://ejurnal.unil } \\
\text { ak.ac.id/index.php/ } \\
\text { agr }\end{array}$ \\
\hline 9 & $\begin{array}{l}\text { Jurnal Ilmiah } \\
\text { Pertanian }\end{array}$ & $\begin{array}{l}\text { https://ejurnal.unil } \\
\text { ak.ac.id/index.php/ } \\
\text { jip }\end{array}$ \\
\hline 10 & $\begin{array}{l}\text { Journal } \\
\text { Keteknikan } \\
\text { Pertanian }\end{array}$ & $\begin{array}{l}\text { http://journal.ipb. } \\
\text { ac.id/index.php/jte } \\
\text { p }\end{array}$ \\
\hline
\end{tabular}

\begin{tabular}{|c|c|c|}
\hline 11 & $\begin{array}{l}\text { Agrotrop: } \\
\text { Journal on } \\
\text { Agriculture } \\
\text { Science }\end{array}$ & $\begin{array}{l}\text { http://ojs.unud.ac.i } \\
\text { d/index.php/agrot } \\
\text { rop }\end{array}$ \\
\hline 12 & Agric & $\begin{array}{l}\text { http://ejournal.uks } \\
\text { w.edu/agric }\end{array}$ \\
\hline 13 & $\begin{array}{l}\text { Jurnal } \\
\text { Teknologi dan } \\
\text { Industri } \\
\text { Pertanian } \\
\text { Indonesia }\end{array}$ & $\begin{array}{l}\text { http://jurnal.unsyi } \\
\text { ah.ac.id/TIPI }\end{array}$ \\
\hline 14 & $\begin{array}{l}\text { International } \\
\text { Journal of } \\
\text { Agriculture } \\
\text { System }\end{array}$ & $\begin{array}{l}\text { http://pasca.unhas } \\
\text {.ac.id/ojs/index.ph } \\
\text { p/ijas/index }\end{array}$ \\
\hline 15 & $\begin{array}{l}\text { JRST: Jurnal } \\
\text { Riset Sains dan } \\
\text { Teknologi }\end{array}$ & $\begin{array}{l}\text { http://jurnalnasio } \\
\text { nal.ump.ac.id/inde } \\
\text { x.php/JRST }\end{array}$ \\
\hline 16 & $\begin{array}{l}\text { Planta Tropika } \\
\text { Journal of Agro } \\
\text { Science }\end{array}$ & $\begin{array}{l}\text { http://journal.umy } \\
\text {.ac.id/index.php/pt }\end{array}$ \\
\hline 17 & Agritech & $\begin{array}{l}\text { http://jurnal.ugm. } \\
\text { ac.id/agritech }\end{array}$ \\
\hline No. & Nam & Alamat \\
\hline 18 & Agro & $\begin{array}{l}\text { http://journal.trun } \\
\text { ojoyo.ac.id/agroint } \\
\text { ek/index }\end{array}$ \\
\hline 19 & $\begin{array}{l}\text { Rona Teknik } \\
\text { Pertanian }\end{array}$ & $\begin{array}{l}\text { http://www.jurnal. } \\
\text { unsyiah.ac.id/RTP }\end{array}$ \\
\hline 20 & Jurnal Agro & $\begin{array}{l}\text { http://journal.uins } \\
\text { gd.ac.id/index.php } \\
\text { /ja/ }\end{array}$ \\
\hline 21 & $\begin{array}{l}\text { Indonesian } \\
\text { Journal of } \\
\text { Agricultural } \\
\text { Science } \\
\end{array}$ & $\begin{array}{l}\text { http://ejurnal.litba } \\
\text { ng.pertanian.go.id/ } \\
\text { index.php/ijas }\end{array}$ \\
\hline 22 & $\begin{array}{l}\text { Jurnal } \\
\text { Manajemen \& } \\
\text { Agribisnis } \\
\end{array}$ & $\begin{array}{l}\text { http://journal.ipb. } \\
\text { ac.id/index.php/jm } \\
\text { agr/index }\end{array}$ \\
\hline 23 & $\begin{array}{l}\text { Jurnal } \\
\text { Agroekoteknol } \\
\text { ogi }\end{array}$ & $\begin{array}{l}\text { https://jurnal.unti } \\
\text { rta.ac.id/index.php } \\
\text { /jav }\end{array}$ \\
\hline 24 & $\begin{array}{l}\text { Jurnal } \\
\text { Teknologi } \\
\text { Pertanian }\end{array}$ & $\begin{array}{l}\text { http://jtp.ub.ac.id/ } \\
\text { index.php/jtp }\end{array}$ \\
\hline 25 & $\begin{array}{l}\text { Journal of } \\
\text { Tropical } \\
\text { Biodiversity } \\
\text { and } \\
\text { Biotechnology }\end{array}$ & $\begin{array}{l}\text { https://journal.ug } \\
\text { m.ac.id/jtbb/index }\end{array}$ \\
\hline 26 & $\begin{array}{l}\text { Ilmu Pertanian } \\
\text { (Agricultural } \\
\text { Science) }\end{array}$ & $\begin{array}{l}\text { https://jurnal.ugm. } \\
\text { ac.id/jip }\end{array}$ \\
\hline 27 & Jurnal & tttp://tpa.fateta.u \\
\hline
\end{tabular}




\begin{tabular}{|c|c|c|}
\hline & $\begin{array}{l}\text { Teknologi } \\
\text { Pertanian } \\
\text { Andalas }\end{array}$ & $\begin{array}{l}\text { nand.ac.id/index.p } \\
\text { hp/JTPA }\end{array}$ \\
\hline 28 & Agrovigor & $\begin{array}{l}\text { http://journal.trun } \\
\text { ojoyo.ac.id/agrovig } \\
\text { or }\end{array}$ \\
\hline 29 & Agriekonomika & $\begin{array}{l}\text { http://journal.trun } \\
\text { ojoyo.ac.id/agrieko } \\
\text { nomika/index }\end{array}$ \\
\hline No. & Nama Jurnal & Alamat \\
\hline 30 & $\begin{array}{l}\text { Jurnal } \\
\text { Penyuluhan }\end{array}$ & $\begin{array}{l}\text { http://journal.ipb. } \\
\text { ac.id/index.php/ju } \\
\text { pe }\end{array}$ \\
\hline 31 & $\begin{array}{l}\text { Jurnal } \\
\text { Perlindungan } \\
\text { Tanaman } \\
\text { Indonesia } \\
\end{array}$ & $\begin{array}{l}\text { https://jurnal.ugm. } \\
\text { ac.id/jpti/index }\end{array}$ \\
\hline 32 & $\begin{array}{l}\text { Jurnal } \\
\text { Agrosains dan } \\
\text { Teknologi }\end{array}$ & $\begin{array}{l}\text { https://jurnal.umj. } \\
\text { ac.id/index.php/fta } \\
n\end{array}$ \\
\hline 33 & $\begin{array}{l}\text { Agrin: Jurnal } \\
\text { Penelitian } \\
\text { Pertanian }\end{array}$ & $\begin{array}{l}\text { http://jurnalagrin. } \\
\text { net/ }\end{array}$ \\
\hline 34 & $\begin{array}{l}\text { Jurnal Ilmu } \\
\text { Pertanian } \\
\text { Indonesia }\end{array}$ & $\begin{array}{l}\text { http://journal.ipb. } \\
\text { ac.id/index.php/JIP } \\
\text { I/index }\end{array}$ \\
\hline 35 & $\begin{array}{l}\text { Sains Tanah: } \\
\text { Journal of Soil } \\
\text { Science and } \\
\text { Agroclimatolog } \\
\text { y }\end{array}$ & $\begin{array}{l}\text { http://jurnal.fp.un } \\
\text { s.ac.id/index.php/t } \\
\text { anah }\end{array}$ \\
\hline 36 & $\begin{array}{l}\text { Gontor } \\
\text { Agrotech } \\
\text { Science Journal }\end{array}$ & $\begin{array}{l}\text { http://ejournal.uni } \\
\text { da.gontor.ac.id/ind } \\
\text { ex.php/agrotech/i } \\
\text { ndex }\end{array}$ \\
\hline
\end{tabular}

Sumber: doaj.org, data diolah 2018

Berdasarkan jenis penerbit, sebagian besar penerbit jurnal ilmiah bidang pertanian Indonesia yang terindeks DOAJ berasal dari penerbit perguruan tinggi. Hal ini sejalan dengan yang dituliskan oleh Tamizhchelvan dan Dhanavandan. Menurut mereka, jurnal yang bersifat open access sebagian besar berasal dari institusi perguruan tinggi, lembaga riset, dan institusi pemerintahan (Tamizhchelvan dan Dhanavandan, 2014). DOAJ merupakan direktori jurnal yang bersifat open access, oleh karena itu penerbit jurnal ilmiah bidang pertanian Indonesia didominasi oleh institusi perguruan tinggi.Hanya satu jurnal yang berasal dari non perguruan tinggi, yaitu Indonesian Journal of Agricultural Science yang diterbitkan oleh Balitbang Pertanian.

\section{Gambar 1}

Penerbit Jurnal Ilmiah Bidang Pertanian Indonesia di DOAJ

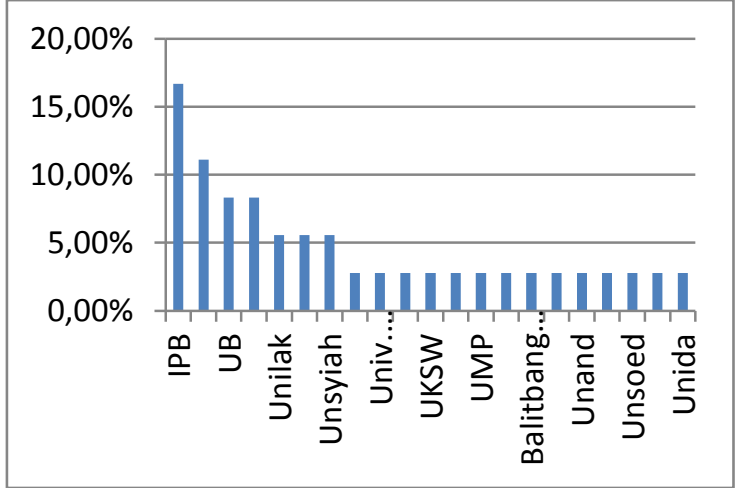

Sumber: doaj.org, diolah 2018.

Data di atas menunjukkan bahwa jurnal ilmiah bidang pertanian yang terbit di Indonesia dan terindeks DOAJ sebagian besar berasal dari IPB $(16,67 \%$ atau 6 jurnal). Selain IPB, perguruan tinggi lain yang juga banyak menerbitkan jurnal ilmiah bidang pertanian yang terindeks DOAJ adalah UGM $(11,11 \%$ atau 4 jurnal), Univ. Trunojoyo dan UB (masing-masing 8,33\% atau 3 jurnal), Unilak, UMY, dan Unsyiah (masing-masing $5,56 \%$ atau 2 jurnal), dan berbagai institusi lainnya (masing-masing menerbitkan 1 jurnal atau $2,78 \%)$.

Berdasarkan biaya penerbitan, jurnal ilmiah bidang pertanian di Indonesia yang terindeks DOAJ didominasi oleh penerbit yang mengenakan biaya penerbitan. Sebanyak 19 jurnal $(52,78 \%)$ dikenai biaya penerbitan bagi penulis yang ingin menerbitkan artikelnya pada jurnal bersangkutan. Sedangkan $17(47,22)$ sisanya merupakan jurnal yang tidak mengenakan biaya penerbitan bagi penulis artikel.

Gambar 2

Kategori Jurnal Berdasarkan Biaya Penerbitan

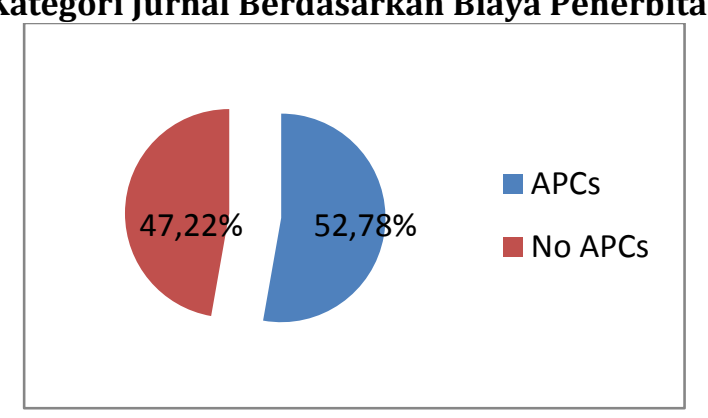

Sumber: doaj.org, diolah 2018

Gambar 3 


\section{Kategori Jurnal Berdasarkan Besaran Biaya Penerbitan}

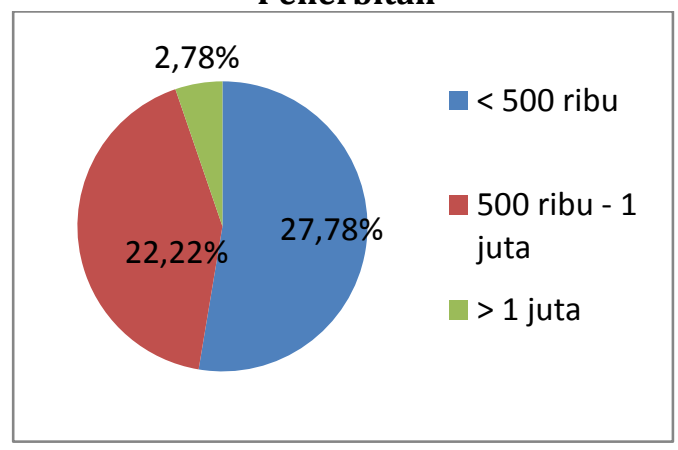

Sumber: doaj.org, diolah 2018

Data di atas menunjukkan bahwa besaran biaya yang dibebankan kepada penulis cukup beragam. Biaya yang dibebankan oleh penerbit kepada penulis artikel sebagian besar berada pada kisaran kurang dari 500 ribu. Meskipun terdapat penerbit yang membebankan biaya sebesar lebih dari satu juta, namun jumlah tersebt sangat terbatas, yaitu hanya 2,78\%.

Pembebanan biaya kepada penulis dalam penerbitan jurnal merupakan hal yang wajar. Terlebih lagi jika jurnal yang dimaksud merupakan jurnal yang bersifat open access. Pembebanan biaya tersebut pada umumnya berlaku bagi para penulis yang menghendaki artikelnya dapat diakses secara bebas (freely accessible) oleh masyarakat luas (Kocher dan Kelly, 2016).

ilmiah bidang pertanian dari Indonesia pertama kali terdaftar di DOAJ pada tahun 2013. Pada tahun tersebut terdapat 1 jurnal yang terdaftar, yaitu Jurnal Manajemen \&Agribisnis. Jurnal tersebut diterbitkan oleh IPB.

\section{Gambar 4}

Perkembangan Jurnal Ilmiah Bidang Pertanian dari Indonesia di DOAJ

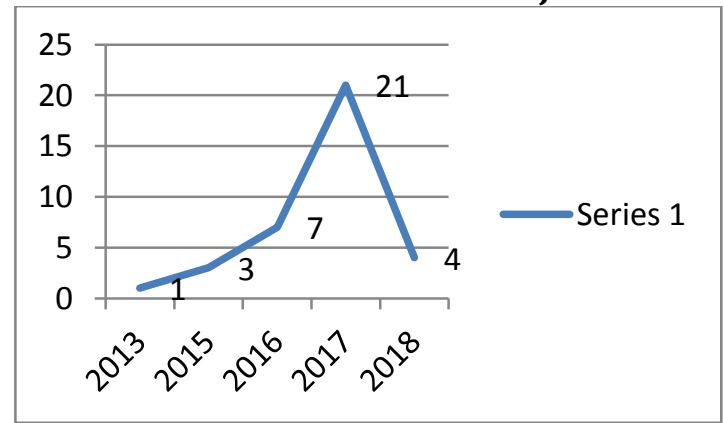

Sumber: doaj.org, diolah 2018
Gambar di atas menunjukkan bahwa jumlah jurnal bidang ilmiah bidang pertanian dari Indonesia yang terdaftar di DOAJ cenderung mengalami peningkatan setiap tahunnya. Peningkatan yang cukup drastis terjadi pada tahun 2017, yaitu berjumlah 21 jurnal. Jumlah tersebut meningkat tiga kali lipat dibandingkan pada tahun sebelumnya yang hanya berjumlah 7 jurnal. Kondisi ini menunjukkan bahwa semangat pengelola jurnal untuk mendaftarkan jurnalnya ke DOAJ semakin meningkat setiap tahunnya.

Berdasarkan proses review artikel, sebanyak 14 jurnal $(38,89 \%)$ menggunakan proses peer review dalam proses penerbitan artikel. 13 Jurnal lainnya (36,11\%) menggunakan proses double peer review. Sedangkan 9 jurnal lainnya (25,00\%) menerapkan blind peer review.

Gambar 5

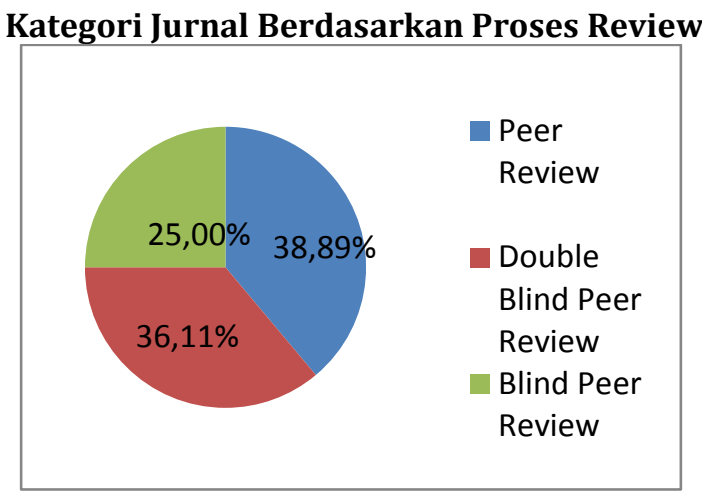

Sumber: doaj.org, diolah 2018.

Proses review merupakan hal yang penting dalam penerbitan jurnal. Proses inilah yang membedakan dengan proses penerbitan lainnya. Salah satu ciri dari jurnal berkualitas adalah jurnal yang selalu menggunakan setidaknya proses peer review (Gunawan, 2018). Proses ini penting dilakuan untuk menjaga kualitas artikel yang akan diterbitkan.

Selain proses review, hal penting lainnya yang perlu diperhatikan dalam penerbitan jurnal adalah terkait lisensi. Lisensi memberikan kepastian hukum bagi pengelola dan penulis untuk menerbitkan artikel pada suatu jurnal. Keberadaan lisensi juga akan memberikan kemudahan dalam pemanfaatan hak kekayaan intelektual yang dihasilkan. 


\section{Gambar 6}

Lisensi pada Jurnal Bidang Pertanian Indonesia terindeks DOAJ

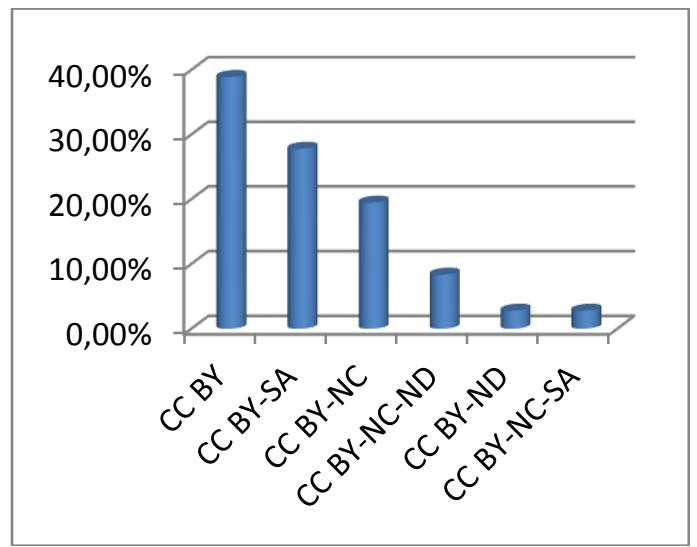

Sumber: doaj.org, diolah 2018

Gambar di atas menunjukkan bahwa lisensi yang paling banyak digunakan oleh penerbit jurnal bidang pertanian Indonesia terindeks DOAJ dalah lisensi CC BY (14 jurnal atau 38,89\%). Lisensi lainnya yang juga banyak digunakan adalah CC BY-SA (10 atau 27,78\%) dan CC BY-NC (7 atau 19,44\%).

\section{Simpulan}

Perkembangan jurnal ilmiah bidang pertanian Indonesia pada DOAJ terlihat semakin menggeliat dari tahun ke tahun. Meskipun demikian, jika dilihat dari jumlah keseluruhan jurnal yang terindeks, jumlah jurnal ilmiah bidang pertanian yang berasal dari Indonesia pada DOAJ perlu terus didorong agar semakin meningkat jumlahnya. Hal ini tentu saja perlu melibatkan berbagai pihak, terutama para penerbit dan pengelola jurnal untuk mendaftarkan jurnal yang dikelolanya pada portal DOAJ.

\section{Daftar Pustaka}

Bachtiar, Arif Cahyo. (2016). Membangun Media Komunikasi Ilmiah di Perpustakaan Perguruan Tinggi.Pustakaloka, 8 (2), hlm.173-184.

Gunawan, Putu Harry. (2018). How to Review a Journal Article.Disampaikan pada Bimtek Penulisan dan Penerbitan Jurnal Nasional Bagi Dosen Perguruan Tinggi di Lingkungan Kopertis Wilayah IV, 24 Maret 2018.Diakses pada https://www.kopertis4.or.id/wp-
content/uploads/2018/03/Dr.-Putu-

How_to_Review_a_jurnal_article_PHN.pdf/ 8 September 2018, 13:19 WIB.

Hazrati, Khairina. (2017). Peran Perpustakaan Sebagai Media Komunikasi Ilmiah.Jurnal Iqra', 11 (1), hlm.29-47.

Kocher, Megan dan Jullie Kelly. (2016). Use of the Paid Open Access Option in Hybrid Open Access Journal in Agriculture: a Mixedmethods study. Issue in Science and Technology Librarianship, 2016 (95).

Lasa Hs. (2009).Kamus Kepustakawanan Indonesia.Yogyakarta: Pustaka Book Publisher.

Marchitelli, Andrea, Paola Galimberti, Andrea Bollini, dan Dominic Mitchel. (2017). Improvement of Editorial Quality of Journals Indexed in DOAJ: a Data analysis. JLIS.it, 8 (1), hlm.2-21.

Olijhoek, Tom, Dominic Mitchell, dan Lars Bjørnshauge. (2015). Criteria for Open Access and Publishing.ScienceOpen Research, 2015, diakses

padahttps://www.scienceopen.com/document _file/85a98041-8734-4a43-b6ebff5903f3ae96/ScienceOpen/3226_XE4097600 663973033675.pdf/, 09 September 2018, 04:52 WIB.

Prasetyawan, Yanuar Yoga. (2017). Perkembangan Open Access dan Kontribusinya bagi Komunikasi Ilmiah di Indonesia.Anuva, 1(2), hlm.93-100.

Stevenson, Janet dan P. H. Collin.(2006). Dictionary of Information and Library Management. London: A \& C Black.

Tamizhchelvan, M. dan S. Dhanavandan.(2014). A Study on Open Access Journals from South Asian Countries Regstered in DOAJ.International Research: Journal of Library \& Information Science, 4 (3), hlm. 443-456. 